\title{
Determinants of Household Poverty: The Case of Shashemene Town, Oromia, Ethiopia
}

\author{
Barke Dekeba Balcha \\ Madda Walabu University, College of Business and Economics
}

\begin{abstract}
Ethiopia is one of the world's poorest countries by any standards. As a result government, multilateral agencies and other stakeholders consider poverty as their priority issues. This study is the study on determinants of urban poverty with the objective of identifying the poor from non poor households and main factors those push them to the poverty trap. Cost of Basic Needs $(\mathrm{CBN})$ approach is used to calculate food poverty line and total poverty line respectively. Out of the 381 surveyed household heads, 170(44.62\%) of them were found poor. A total of 381 respondents were included in the survey and the main data for the study was collected through structured questionnaire. Binary Logit model was employed to analyze the determinants of households' poverty. Fourteen explanatory variables were taken in to account in the model's equation. The result of logit regression using STATA13.1 software confirmed that nine variables were found statistically significant; age of households (1\%), income of house hold head (1\%), marital status of households $(1 \%)$, house tenure of households $(1 \%)$, household family size (1\%), households employment status( $1 \%)$,educational level of households $(5 \%)$, access to credit $(5 \%)$ and saving(10\%). From these significant variables; age of households, households' family size, households' marital status and households housing tenure were positively correlated with probability of being poor. While households education, households income, households saving, households employment status and households access to credits were negatively correlated with probability of being poor. Two sample t-test and chi-squared test was employed to compare non-poor and poor. The poverty head count ratio is extensive among the surveyed households that calls for urgent interventions aimed at solving the problems of the poor. Hence efforts should be made to increase the real income of households through well paying and better job creation by the set up of micro and small scale enterprises, with the increased provision of economic and social infrastructure. Thus, stakeholder interventions to tackle the determinant factors are important measures to be undertaken.
\end{abstract}

Keywords: Poverty, Household, Logit Model, Shashemene, Ethiopia

DOI: $10.7176 / \mathrm{JESD} / 12-7-01$

Publication date: April $30^{\text {th }} 2021$

\section{Back ground of the study}

Poverty has been considered as the condition that is said to exist when people lack the means to satisfy their basic needs such as food, shelter and clothes. For instance, World Bank has defined poverty as "the inability to attain a minimum standard of living" (World Bank, 2007). Poverty is a pervasive reality of the world. It is a world's greatest challenge in the 21 st century. Based on estimates of international poverty lines, world population live on less than $\$ 1.25$ a day), 12 countries managed to reduce poverty levels between 1990 and 2005 . Although these declines are encouraging, they still leave a large proportion of the total population living in extreme poverty, and all 19 countries face major challenges in meeting the 2015 Millennium Development Goal target (World Bank, 2013). Based on the international poverty line of the year 1999, 44 percent of the world population is absolutely poor (MoFED, 2002). For instance, reports that $23 \%$ of the world population survives on less than $\$ 1.25$ a day and $77.8 \%$ live on less than $\$ 2$ a days (World Bank 2006).

In Africa, particularly Sub Saharan countries (SSC) economic performance has been markedly worse than that of other regions. The great majority of Africans live on barely $\$ 0.65$ a day and this number is decreasing persistently (WB, 2000). The rural poor accounts of $80 \%$ of African poverty, while urban poverty was substantial and appears to be growing. People in SSC were among the poorest in the world both in real incomes and in access to social services. Among 300 million people in Sub-Saharan Countries, almost half of the region's population lives on less than $\$ 1$ a day (UNDP, 2006).

Ethiopia is one of the world poorest countries by any standards. It is known all over the world where citizens live in very chronic condition of poverty. Poverty and low level of welfare is widespread in Ethiopia according to official sources (MoFED, 2007). This could be while urban life is complex and predominantly monetized economy that of rural was basically determined by assets on land, number of oxen, cows, sheep, goats, extra available to the farmer. The incidence of urban poverty measured by the headcount index in 1995/96 was $51.6 \%$. That is, more than half of the population was poor in $1995 / 1996$. While this share of the poor declined to $38.5 \%$ in 2004/05 (Tassew et al., 2008; Bigsten et al., 2005), the country is still in the lowest rank as compared to other countries based on both human development and poverty indices.

The Human Poverty Index (HPI-1) focuses on the proportion of people below a threshold level in the same dimensions of human development as the HDI such as living a long and healthy life, having access to education, 
and a decent standard of living (based on the $\$ 1.90$ a day poverty line at PPP poverty measure). It is $51.5 \%$ for Ethiopia ranking the country $173^{\text {rd }}$ among 189 countries for which the index has been calculated (http://hdr.undp.org, UNDP, 2018).

Although Ethiopia has long been known as the frame of humanity, poverty remains magnificently common and persistent. By any standard, the majority of people in Ethiopia are among the poorest in the world. Ethiopia has achieved a remarkable economic growth on average of $10.6 \%$, in comparison with an average population growth rate of $2.6 \%$; this implies that the average annual per capita income growth rate was $8.4 \%$. However, because of high population growth, the absolute number of the poor has remained unchanged at some 25 million over the past 15 years. Poverty head count has fallen from $45.5 \%$ in 1995 to $26.0 \%$ in 2012/2013. The poverty gap was also reduced but not the severity of poverty. The country is registered to be the poorest in Sub-Saharan Africa with a Human Development Index of 0.448 and Multidimensional Poverty Index of 0.564, which gives a rank of 174 out of 188 and second from the last (Niger) (MoFED, 2012; UNDP, 2015; OPHI, 2016).

High population growth due to migration and other internal factors have making life hard in urban Ethiopia. This really can lead to high crime, strikes and other socio economic and political problems. Therefore, the issues addressed in this study can help the government to design strategies to tackle the real problem of urban areas in general and the study area in particular.

In Ethiopia, studies show that urbanization is growing at a faster rate. According to Ministry of works and Urban Development(MWUD),(2006), there are above 925 urban centers at different growth stages in Ethiopia and annual urban population growth rate is estimated to be above $4.84 \%$ (World bank in 2014). This rate depicts that the population of urban areas is increasing by a half million people every year. Today, the population of urban centers is about 12 million and this comprises $16 \%$ of the total population of the country. The total urban population of the country will be 17.8 million by 2015 and 22 million by 2020 . The combination of urban growth that is amongst the highest in the world with the high prevalence of urban poverty suggests a rapidly growing number of urban poor (PASDEP, 2006).

Given the above figure, the government of Ethiopia pursued urban development strategy including medium and small size towns on the second phase of Poverty Reduction Strategic Paper (PRSP) (2006-2010) called Plan for Accelerated and Sustainable Development to End Poverty (PASDEP) than the first phase of PRSP. However, still gives mere weight on rural development. In addition to giving less attention to urban issues, the major weakness of the first phase of PRSP was its lack of detail information for implementation and monitoring the strategy as cited in (Esubalew, 2006). This problem now incorporated in PASDEP. However, PASDEP to emphasized on sector strategies rather than having specific policy for directing strategies and achieving goals and objectives.

This paper should help to re examine urban poverty reduction strategy and goals in the city and for medium size towns by way of analyzing its determinants. The fundamental question that comes in the fore front is who are poor and what factors determine to be poor. Therefore, the issues addressed in this study can help the government to design strategies to tackle the real problem of urban areas in general and the study area in particular.

\section{Statement of the problem}

In Ethiopia poverty is the general feature of the nation and cause many suffering and unhappiness to the largest proportion of the population. It is priority area of the government, donor agencies, NGOs and other actors that have initiative to reduce its level and mitigate the effect and its associated impacts on the well -being of the people. Urban poverty has been given less concern on research and development plan of Ethiopia particularly for medium towns like Shashemene. The Ethiopian government has formulated and implemented various policy interventions and programs that are in one or another way related with poverty reduction. Yet most efforts were biased towards rural areas.

Most poverty literatures in Ethiopia dominate in rural areas. They concentrate on food entitlement failures of farmers. MoFED (2013), for example, study the status of poverty in rural Ethiopia by taking the income portfolios and food entitlements of households. MoFED (2012) adopt a sociological approach to analyze rural poverty. They explored the importance of social class and family relationships including the extended family in the fight against poverty. They concluded that in rural Ethiopia social capital are very important in the way out of poverty.

Though in absolute terms poverty is still a rural phenomenon, there is currently a diffusion and growth of urban poverty. The number of urban poor is increasing at an alarming level that might be caused by the highest rural-urban migration and alarming internal population growth (Esubalew, 2006). In the meantime, the urban economy has limited capacity to accommodate the unprecedented population explosion. More specifically, being employed in the formal sector is really difficult, though the effects of urban poverty in Ethiopia are getting severe. The factors that account for the results are not studied very well. Most studies have been conducted in rural areas and attempts made on urban centers are still less (MoFED, 2002). 
Even the studied ones are confined to the major city-Addis Ababa or secondary towns like Nazareth, Bahir Dar, Mekelle, Awassa, Gondar, Debre Markos and Woldia (EEA, 2002) but not in the specified area. Mohammed (2009) has conducted study on determinants of urban poverty: the case of Woldia. His study explained that, Poverty status and the determinant could be varying over time. For this reason the researcher attempted to undertake this study by including saving, rural-urban migration and employment as the causes of poverty at Zonal level. However, household poverty was a major problem of Shashemene town.

The challenge in the fight against poverty of the medium towns in the country in general and in Shashemene town in particular is huge. One of the challenges in the fight against poverty is clear identification of the prevailing obstacles. Examination of some impeding variables which aggravate poverty is vital. Among the many impediments of poverty are the, social services, economic and demographic variables. Identifying their potential effects on poverty is critical in the study of urban poverty since these variables take the visible effects on the creditable life of urban dwellers.

Shashemene is one of the oldest and medium towns of Ethiopia currently facing with discouraging socioeconomic and demographic challenges. The economic activity and social infrastructure of the town is low and the overall life standard of the inhabitants is not in a good condition (Planning and Economic Development Shashemene town, Shashemene (2017). Therefore, this study examined household poverty in Shashemene town. As to best of my knowledge no study dealing with Determinants of poverty was conducted in the study area .Therefore, this study was attempt to fill this gap in addition to come up with the solutions for the existing problems in this study area.

\section{DATA AND RESEARCH METHODOLOGY}

\subsection{Description of the Study Area}

The study would be conducted in Shashemene town, which is one of the oldest town established in 1910G.C. Shashemene town is found in Oromia regional state, west Arsi zone. Shashemene's urban local Government, administration of self rule by the town was incorporated among the 20 selected towns in Oromia Regional state and reformed in 2005 in accordance with the proclamation No. 65/2003. The objective of the reform was to tackle the imbalance of life condition, lack of infrastructural services in the urban due to increasing rural-urban migration, shortage of residence, unemployment, aggravated poverty and its consequence such as crime, ill health that emanated from lack of sanitation, environmental pollution in the settlement of urban dwellers. The town is located at a distance of $250 \mathrm{~km}$ south of Addis Ababa along the Trans-African High way. Geographically, it is located at an approximate coordinates of $7008^{\prime} 51^{\prime \prime} \mathrm{N}$ to $7018^{\prime} 19^{\prime}$ ' $\mathrm{N}$ latitude and $38032^{\prime} 43^{\prime}$ 'E 380 41' 07 ''E longitude.

The topography of the town has almost gentle slope. According to the urban slope classification, the area that accounts about $32.5 \%, 23 \%, 19.9 \%$, and $13.6 \%$ covering the ranges between $2-3 \%, 4.5 \%, 0.2 \%$ and $6-7 \%$ respectively. The maximum and minimum altitude is about $1794 \mathrm{~m}$ to $2094 \mathrm{~m}$ above sea level. The highest altitude is recorded at South East and North East part of the town and the lowest altitude is located in South west and Western parts of the town. The largest urban area is covered in the elevation of $1967-2009 \mathrm{~m}(21.7 \%)$. This is followed by the elevation that ranges between 1924-1966m (21.1\%) and 1881-1923m (18.9). The proportion of an elevation that range between 1794-1837m (6.6\%) and 2052-2094m (3\%).

The drainage system of the town is found in the Shalla lake basin which is found in the North-western part of the town at a distance of about $50 \mathrm{~km}$. The entire elevation of the town lies within sub-tropical climate zone. The mean annual maximum temperature of the town is about $26.5^{\circ} \mathrm{C}$. The mean monthly and annual range of temperature is about $3.8^{\circ} \mathrm{C}$ and $4.7^{\circ} \mathrm{C}$ respectively. The town also got high amount of rain fall in spring and autumn season. The town gets yearly total annual rain fall which ranges between $570-980 \mathrm{~mm}$.

The town has eight urban administrative sub towns namely; Awasho(kebele 01), Abosto(kebele 02 and 03), Dida Boke(kebele 04), Bulchana(kebele 05), Burka Gudina(kebele 06 and 07), Arada(kebele 08 and 09), Alelu(kebele 10), and Kuyera(kebele 11 and 12). 

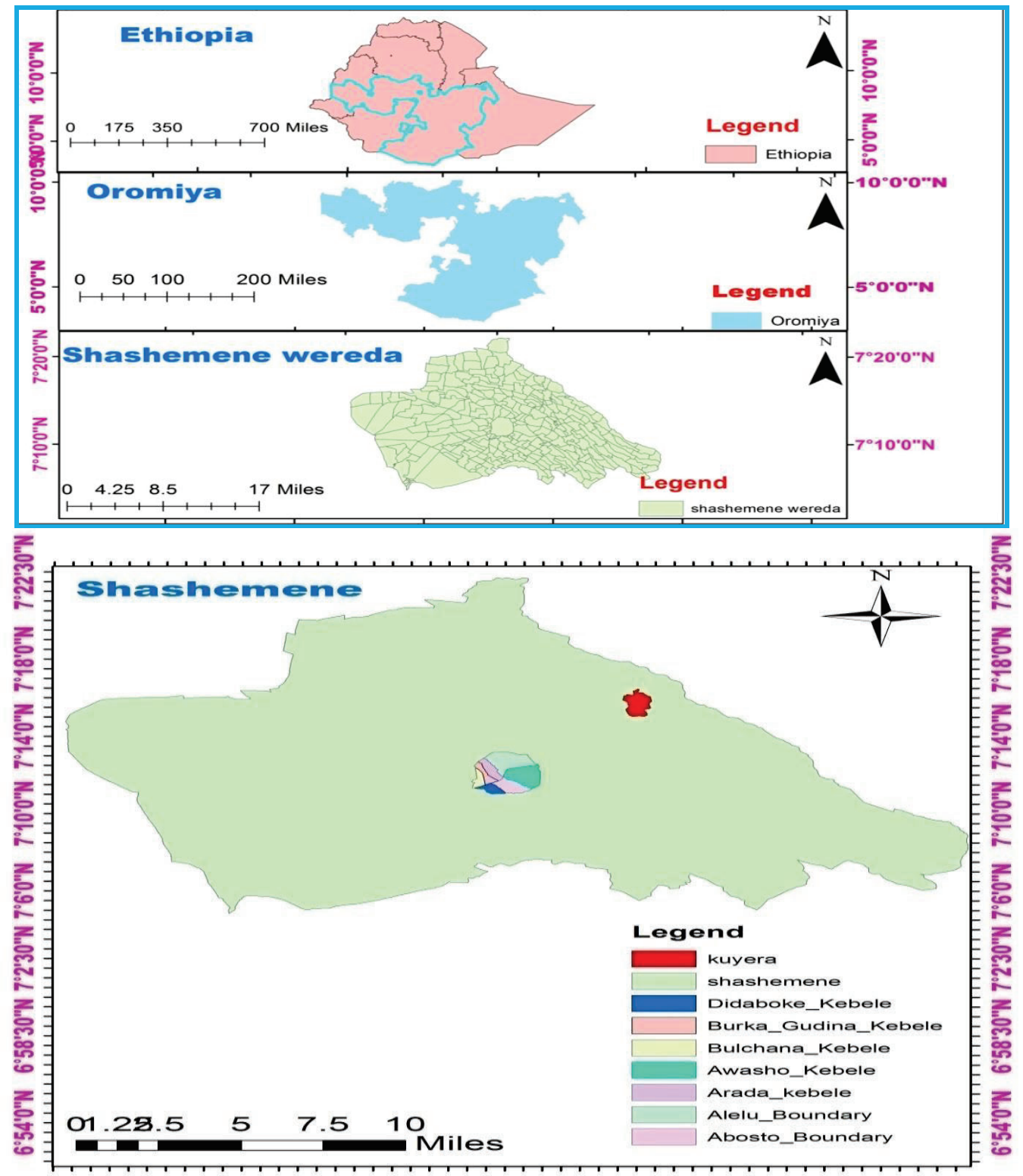

Fig1.3. Geographical Location of the Study Area Source: GIS archives (2019)

\subsection{Sampling size and sampling technique}

\subsubsection{Sample size}

The researcher employed a cross-sectional survey to asses determinant of households poverty in Shashemene town, from the eight kebeles 381 sample size was determined using mathematical formula developed by Kothari (2004:179) was used...

$$
n=\frac{(Z) 2 x(p x q) N}{(e) 2(N-1)+(Z) 2 x(p x q)}
$$

\section{Where;}

$\mathrm{n}=$ Household sample size

$\mathrm{N}=$ Total household population size registered in kebele office $=50,308$

$\mathrm{e}=$ Degree of precision $=0.05 \%=$ with the given level of confidence $95 \%$

$\mathrm{Z}=$ Confidence level $=1.96$

$\mathrm{p}=0.5$ (sample proportion). $\mathrm{q}=0.5\{(1-0.5)$ i.e. $1-\mathrm{p}\}$

$n=\frac{(1.96) 2 x(0.5 \times 0.5) 50,308}{(0.05) 2(50,308-1)+(1.96) 2 x(0.5 \times 0.5)}=381$ 


\subsubsection{Sampling techniques.}

The sampling technique employed by the researcher was a random sampling technique so that each household would have equal chance to be selected. The town has Eight sub towns namely; Awasho(kebele 01), Abosto(kebele 02 and 03), Dida Boke(kebele 04), Bulchana(kebele 05), Burka Gudina(kebele 06 and 07), Arada(kebele 08 and 09), Alelu(kebele 10), and Kuyera(11 and 12). Based on this administrative division, eight kebeles were taken to collect data. The sampled kebeles are 01, 03, 04, 05, 07, 08, 10 and 12. They were selected randomly to have one kebele from each sub town. Finally, 381 households were randomly selected from each representative kebeles by using probability proportional to size. The sample frame is registered household list collected through census by Population and Vital Statistics Office of the Administration Council with technical support of Central Statistical Authority and the list will be updated whenever new household come to the town as a resident and seeks to obtain any service.

\subsection{Methods of data analysis and interpretation}

Basically the analysis and presentation of the study is quantitative. In the first part, the research used descriptive statistics (percentages, means, standard deviations, Chi-squares, significance intervals, test and t-test). These were analyzed and described quantitatively by making use of STATA software 13.1 version, and tables. In the second part econometric issues, more specifically, Logit model is adopted. Variables, which play significant roles for the incidence of poverty in Shashemene, were analyzed through this model by making use of econometric issues. In this part STATA13 software was employed to determine the coefficients of the determinants odds, odds ratio and test the statistical significance relationships between the determinants and the dependent variable of (urban poverty).

\subsection{Research Design}

\subsubsection{Measurement and Decomposition of Poverty}

This study applied Cost of Basic Need (CBN) approach in the computation of poverty lines. Because, CBN approach can better explain urban poverty because urban poverty is mostly characterized by monetized economy and lack of basic services. The problem is related not only to food poverty but also to non food items like house rent, educational fees, transport and others are equally important and involve substantial cost. Logit model would be used when the dependent variable become dichotomous that takes values as households are poor and non poor .In order to identify the determinants of poverty. Logistic regression model would be employed. The explanatory variables are considered to be socio-economic and demographic characteristics. The impact of predictor variables is usually explained in terms of odds ratio. The form of the Logit model in Gujarati in, (2004) is used.

\subsubsection{Econometrics Model specification}

In order to identify the determinants of poverty a logistic regression model is employed. Logit model is used when the dependent variable become dichotomous that takes values as households are poor (1) and non poor (0). The explanatory variables were considered to be socio-economic and demographic characteristics, which includes gender, age, education, occupation of the household head, family size, income, ownership of house, health, marital status, rural-urban migration, access to credit, access to basic services and education of the household etc. After transforming the dependent variable into logit, maximum likelihood estimation will be employed to determine the coefficients of the variables.

The form of the Logit model in Gujarati in2004 is:

$Y=\alpha+\beta_{1} X_{1}+\beta_{2} X_{2}+\beta_{3} X_{3}+\ldots .+\beta_{k} X_{k}+\mathrm{Ui}$

Where:

$\mathrm{Y}=$ Probability of a household being poor or non-poor

$\alpha=$ Intercept (constant) term

$\beta_{k}=$ Coefficients of the predictors estimated using the maximum likelihood method

$\mathrm{X}_{\mathrm{i}}=$ Explanatory (independent variables)

$\mathrm{U}_{\mathrm{i}}=$ Random effect (error term)

Aggregating the values yields

$\dot{Y}=$

$$
\alpha+\sum_{k=1}^{k} \beta_{k} X_{k}+v_{\iota}
$$


In practice, $\mathrm{Y}$ is unobserved, which indexes the measure of poverty, $\mathrm{U}_{\mathrm{i}}$ is symmetrically distributed with zero mean, and has cumulative distribution function $(\mathrm{CDF})$ defined as $\left(\mathrm{U}_{\mathrm{i}}\right)$. What is observed is an event represented by a dummy variable $\mathrm{Y}$ defined by

$\mathrm{Y}=1$ if $\mathrm{Y}>0$

$\mathrm{Y}=0$ otherwise-

The explanatory variables in our regression model may be called determinants, because the dependent variable is a function of the explanatory variables and, therefore, is determined by them. However, theory holds that many of the variables included in the analysis do indeed contribute to (cause) poverty (or poverty reduction), the statistical relationships should be interpreted as correlates but should be understood as "proximate" causes and not as deep determinants/ causes since causality can run both ways for some variables.

\section{RESULT AND DISCUTION}

\subsection{Descriptive Analysis}

\subsubsection{Setting poverty line}

Setting of poverty line facilitates identification of the poor from non poor. The study applied Cost of Basic Need $(\mathrm{CBN})$ approach in the computation of poverty lines. CBN approach can better explained urban poverty because urban poverty mostly characterized by monetized economy and lack of basic services.

This study derives from the household's consumption expenditure for food and non food. Hence, having such concept for the $\mathrm{CBN}$, the following steps were employed to obtain the poverty line: $2300 \mathrm{kcal}$ as the minimum calorie required per household's per day in Ethiopia, the researcher tried to estimate the cost of meeting this food energy requirement.

\subsection{Descriptive Analysis}

As mentioned earlier under the descriptive analysis, this study is based on socioeconomic and demographic characteristics of the data obtained in household survey of Shashemene town. The whole description takes total poverty line (food plus non-food consumption expenditures) as a reference to identify the poor from the non poor households.

\section{Age and Poverty}

The table below shows the average age of non poor is 43.8 and that of poor were 51.3 and the minimum and maximum years of the respondent were 24 and 70 respectively. Out of total respondent 51(13.4\%) of the sample respondent were economically unproductive \& 330 (86.6\%) were economically active households. As survey data shows that age of households dominated by economically productive one in the study area. The productive age group and the poverty have negative relationship as productive age group increases the probability of being poor decreases. Because as the one goes to the old ages labor productivity decreases leads income decreases and as the age of household increases in the young group the probability being poor increases. The $t$ test shows $t=-$ 6.1160 significant at 1\% level of significant. This finding is confirmed with by Mohammed (2009) in Woldia.

Table 4.1. Age distribution and poverty status of households

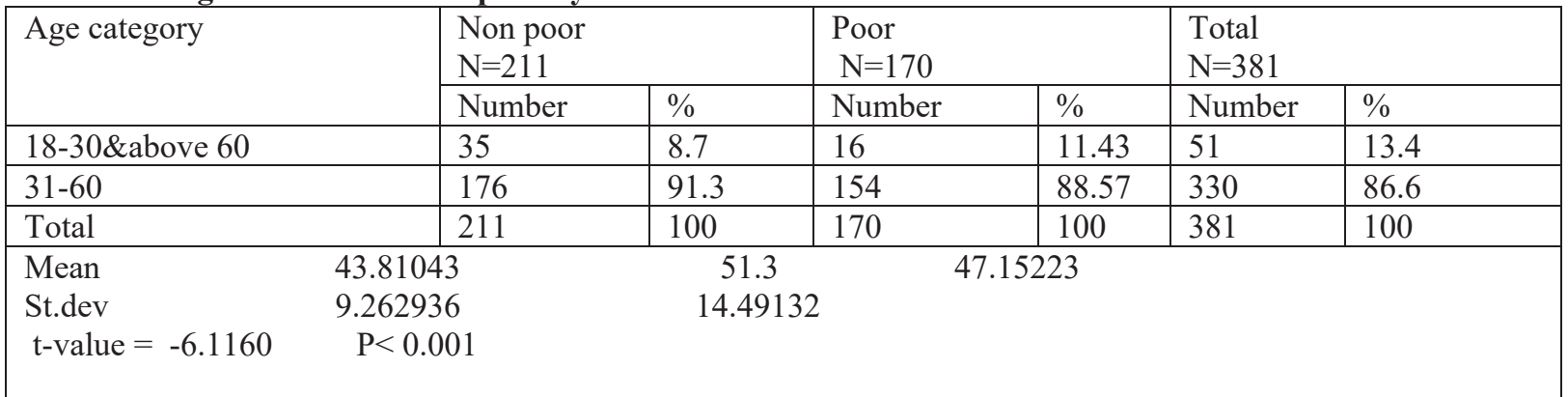

Source: Own computation (2019) Significant at $1 \% *$ t-value $=-6.1160$

\section{Sex and Poverty}

The respondents of this study are found to be $38.32 \%$ female household heads and $61.68 \%$ male household heads was included in the survey. Within female headed households, $54.12 \%$ of them are found to be poor and $30.33 \%$ are non poor. Of the total male headed households only $45.88 \%$ of the male headed are poor and the rest $69.67 \%$ are non poor. From the total of households which lie below the poverty line $54.12 \%$ are female headed and the remaining $45.88 \%$ percent are male headed. The majority of poor are female headed households. But the test of this variable is statically not significant in the study areas, implying that it is not determinants. This result was supported by Esubalew (2006) in Debramarkos, Getachew (2009) in Gondar. 
Table .4.2. Gender and poverty status of Shashemene town.

\begin{tabular}{|l|l|l|l|l|l|l|l|}
\hline Group & Poor & $\%$ & Non-poor & $\%$ & total & P value & Ch2 \\
\hline Male & 78 & 45.88 & 147 & 69.67 & 225 & 0.287 & 0.8083 \\
\hline Female & 92 & 54.12 & 64 & 30.33 & 156 & & \\
\hline Total & 170 & 100 & 211 & 100 & 381 & & \\
\hline
\end{tabular}

Source: Own computation (2019) insignificant at any significant level

\section{Poverty and Household Size}

As per to the table 4.3. the minimum and maximum household size of the study area was 0 and 13 respectively. The average household size was (4.74) approximately six (5) members per household. As shown in the Table 3.4 below, the share of poor households within the category of household size five and below were $25.89 \%$ of the total poor. Households that have household size of above the average family size takes the high share, is $74.11 \%$ of the total poor. Therefore, the majority of households in the study area, who have greater than average family size and above live below poverty line. This shows household family size and poverty has positive relationship. As household family size increases the probability to being poor is increases. A reason could be the high cost of living in the urban areas even for minimum consumption needs, which makes them vulnerable.

The statistical analysis showed a significant different in means of family size between poor and non poor households, which is 5.71 for poor and 3.77 for non poor households. The t-test shows $\mathrm{t}=--7.7489$ and at $1 \%$ significant level. On this, t-test used for continuous variable to compare the mean values of poor and non poor.

Table 4.3. Distribution of Sample Household by Family Size

\begin{tabular}{|l|l|l|l|l|l|l|}
\hline Households & Poor & $\%$ & Non-poor & $\%$ & Total & $\%$ \\
\hline Below five & 44 & 25.89 & 184 & 87.20 & 228 & 59.84 \\
\hline Above five & 126 & 74.11 & 27 & 12.80 & 153 & 40.16 \\
\hline Means & 5.7109 & 3.770588 & 4.737533 \\
St.Dev & 2.70 & 1.62 & & \\
T-test. Value $t=--7.7489 \operatorname{Pr}(\mathrm{T}>\mathrm{t})=0.5807$ & & \\
\hline
\end{tabular}

Source: Author's household field survey of (2019) significant at 1\%

\section{Income of households and poverty}

The households' income starts from birr (200) minimum to birr (24500) maximum per month respectively. Out of this mean income of poor is birr 1055.282 and non poor households, 3864.493 birr per month. There are substantial different between income of the poor and non poor in the study area. The t-test-values $=14.6009$ and significant at $1 \%$ level of significant. This indicating there is significant difference between households income of the poor and non poor is leads the income of some households is very high due-to support from relative and highly from their children living outside Ethiopia. The implication here is that the difference (2809.211) can be either saved/used for other purposes by the household. The $99 \%$ confidence interval for the mean difference indicates that one can save or use for other purposes of 2809.211 birr to the minimum.

Table 4:4. Monthly Income of the household head

\begin{tabular}{|l|l|l|l|l|l|l|}
\hline Group & Obs & Mean & Std. Err. & Std. Dev. & \multicolumn{2}{|c|}{ [95\% Conf.Interval] } \\
\hline Non-poor & 211 & 3864.493 & 167.6966 & 2435.933 & 3533.908 & 4195.077 \\
\hline Poor & 170 & 1055.282 & 51.01031 & 665.093 & 954.5829 & 1155.982 \\
\hline Combined & 381 & 2611.039 & 119.3939 & 2330.476 & 2376.284 & 2845.795 \\
\hline Diff & & 2809.211 & 192.3994 & & 2430.907 & 3187.515 \\
\hline
\end{tabular}

Source: Own computation (2019) significant at1\% $\quad$ t.values $=14.6009$

Poverty and Education of Households

The below table of the survey result showed that households head highest educational level has a significant effect on the probability of being poor or non- poor at $95 \%$ confidence interval. The highest educational level of the household head groups: illiterate, primary (1-8), secondary (9-12), diploma holder, first degree holder, and above first degree holder Esubalew (2006).

From this category the number and percentage share of secondary and diploma holders rank first, 77 $(36.48 \%)$ and $70(33.18 \%)$ and respectively in the above poverty line group. In the below poverty line; however, $65(38.24 \%)$ and $0(0 \%)$ which are the highest and lowest percentage share goes to the primary school completes, degree and above first-degree holders. As one moves away from first degree holder to illiterate ones the probabilities of being poor increases and vice versa. . In study area when we see the proportion of sample respondent which fall below poverty line by their educational level are, illiterate $(0.793 \%)$,primary $(1-8)$ $(0.775 \%)$, Secondary (9-12) $(0.32 \%)$, Diploma Certificate $(0.06)$ and Degree and above $(0 \%)$. Thus, the explaining power of educational level of the household head. The chi-square test $\operatorname{ch}^{2}(1)=4.91 \mathrm{P}>$ value $=0.012$ shows significance at 95 confidence interval, implying that it is the main determinants of poverty in the study areas 
Table.4.5. The distribution households' educational level

\begin{tabular}{|l|l|l|l|l|l|l|}
\hline Education level & Non poor & Poor & \multicolumn{2}{l|}{ Total } \\
\hline & Number & $\%$ & Number & $\%$ & Number & $\%$ \\
\hline Illiterate & 9 & $4.27 \%$ & 48 & $28.24 \%$ & 57 & $14.96 \%$ \\
\hline $1-8$ & 14 & $6.64 \%$ & 65 & $38.24 \%$ & 79 & $20.7 \%$ \\
\hline $9-12$ & 77 & $36.48 \%$ & 50 & $29.40 \%$ & 127 & $33.33 \%$ \\
\hline Diploma \& cert & 70 & $33.18 \%$ & 7 & $4.12 \%$ & 77 & $20.21 \%$ \\
\hline Degree \& above & 41 & $19.43 \%$ & 0 & $0 \%$ & 41 & 10.80 \\
\hline Total & 211 & $100 \%$ & 170 & $100 \%$ & 381 & $100 \%$ \\
\hline
\end{tabular}

Source: Author's household field survey of 2019 significant at 5\%

\section{House Condition and Poverty.}

The Ownership of house in urban areas is really an important indicator of poverty in most developing countries. This indicator is of dominant importance because it is household wealth, which generates income flows. Out of total respondent $168(44.09 \%)$ of households have their own house and 213(55.91\%) have no their own house. Households who are not ownership of house is found positively significant correlated with poverty. As households not own house increases the cost that paid to the house became increases leads expenditure increases, income decreases and poverty increases. The $\operatorname{ch} 2(1)=3.25>$ value $=0.000$ shows as significance at 99 confidence interval, this indicates that housing condition of house hold is the determinants of poverty in the study areas.

Table.4.6.Households housing tenure and poverty.

\begin{tabular}{|l|l|l|l|l|l|l|l|}
\hline Group & Poor & $\%$ & Non-poor & $\%$ & Total & P-values & Ch2 \\
\hline Ownership & 38 & 22.62 & 130 & 77.38 & 168 & 0.000 & 3.25 \\
\hline Rented (from Private) & 110 & 59.46 & 75 & 40.54 & 185 & & \\
\hline Rented (from kebele) & 22 & 78.57 & 6 & 21.43 & 28 & & \\
\hline Total & 170 & 100 & 211 & 100 & 381 & & \\
\hline
\end{tabular}

Source: Own computation 2019 significant at $1 \%$

Employment and poverty

Empirical studies indicate that employment has a high and negative correlation with poverty

(Maru, 2006), However, few research works infer that there is significance difference between the unemployed heads and those who are employed in the informal sector (NIS, 2007). The employment categories of the respondents are classified into two major classes, these are Employed 232(60.89 percent) and unemployed $149(39.11$ percent $)$. The $\operatorname{ch}^{2}(1)=3.61 \mathrm{P}$-value $=0.003$ shows as significance at 99 confidence interval, this indicates that employment status of house hold is the determinants of poverty in the study areas.

Table.4.7.Employment status and poverty in Shashemene Town

\begin{tabular}{|l|l|l|l|l|l|l|l|}
\hline Poverty & Non-poor & $\%$ & Poor & $\%$ & Total & $\mathrm{Ch}^{2}$ & P.value \\
\hline Employed & 174 & 75.17 & 58 & 25.00 & 232 & 3.61 & 0.003 \\
\hline Unemployed & 37 & 24.83 & 112 & 75.00 & 149 & & \\
\hline Total & 211 & 100 & 170 & 100 & 381 & & \\
\hline
\end{tabular}

Source: Own computation 2019 significant at $10 \%$

Saving of the households and poverty

Table 4.8. Below shows that, from the sampled respondents $272(71.39 \%)$ of the them save their money whereas109 (28.61\%) of them do not save their money. This shows that majority of the households in Shashemene town save their money. However, only $37.25 \%$ of the respondents save their money in saving accounts; the remaining (34.14\%) prefer purchasing of physical assets and running their dally business. The study indicates that out of the total population incorporated in this study only $25 \%$ have regular saving those borrowing from different micro finances and the remaining save irregularly, save in physical assets or never save at all. There are high different between saving of the poor and non poor in the study area. The t-test-values= 11.6309and significant at $10 \%$ level of significant. This indicating there is significant different between households saving of the poor and non poor is leads the saving of some households is very high because of income different between poor and non poor households.

Table 4.8. Saving of households and poverty

\begin{tabular}{|l|l|l|l|l|l|l|}
\hline Group & Obs & Mean & Std. Err & Std. Dev. & \multicolumn{2}{|c|}{ [95\% Conf. Interval] } \\
\hline Non-poor & 211 & 1252.389 & 83.96353 & 1219.641 & 1086.869 & 1417.908 \\
\hline Poor & 170 & 142.5882 & 20.8489 & 271.8364 & 101.4304 & 183.7461 \\
\hline Combined & 381 & 757.2021 & 55.17963 & 1077.063 & 648.7064 & 865.6978 \\
\hline Diff & & 1109.8 & 95.41811 & & 922.1852 & 1297.416 \\
\hline
\end{tabular}

Source: Own computation 2019 significant at $\mathbf{1 0 \%}$ t.values $=11.6309$

Marital status of the household and poverty

Marital status of the household head is an important constituent of the demographic variables. But from different 
angles there is positive and vise verse between poverty and marital status of house household head analysis. Separately from the table 9:4 we demonstrate that the probability of being poor is higher among widowed households (95.24) this may be due to the fact that if the household head died who is economically managing and the rest may be inactive. The probability to be poor is also high in the divorced households (84.78) to widowed households. While, from the never married total respondents $(20.38 \%)$ of them are found below poverty line which constitute low probability to be poor. This may be due to having single family size who is productive which leads to high income and less expenditure.

The $\operatorname{ch}^{2}(1)=2.34 \mathrm{P}$-value $=0.004$ shows as significance at 99 confidence interval, this indicates that Marital status of house hold is one of the determinants of poverty in the study area.

Table 4.9.Marital status and poverty in Shashemene Town

\begin{tabular}{|l|l|l|l|l|l|l|l|}
\hline Poverty & Non-poor & $\%$ & Poor & $\%$ & Total & $\mathrm{Ch}^{2}$ & P.value \\
\hline Not Married & 168 & 79.62 & 43 & 20.38 & 231 & 2.34 & 0.004 \\
\hline Married & 35 & 33.98 & 68 & 66.02 & 103 & & \\
\hline Divorced & 7 & 15.22 & 39 & 84.78 & 46 & & \\
\hline Widowed & 1 & 4.76 & 20 & 95.24 & 21 & & \\
\hline Total & 211 & 100 & 170 & 100 & 381 & & \\
\hline
\end{tabular}

Source: Own computation 2019 significant at $\mathbf{1 \%}$

Access to credit services and Poverty

According to table 4.10, in the surveyed area, out of total respondent 203(53.28\%) of households have access to credit and $178(46.72 \%)$ have no access to credit. From the respondents, Households who have no access to credit were found positively significant correlated with poverty. As households inaccessibility to credit increases the probability of the households to be being poor also increases. The $\operatorname{ch} 2(1)=49.06$ P.value $=0.047$ shows as significance at 95 confidence interval, this indicates that access of the of the households to credit is the bolded determinants of poverty in the study areas.

Table 4.10. Households Access to credit services and Poverty

\begin{tabular}{|l|l|l|l|l|l|l|l|l|}
\hline Poverty & Non-poor & $\%$ & Poor & $\%$ & Total & $\mathrm{Ch}^{2}$ & LR chi2(1) & P.value \\
\hline Have Access to credit & 146 & 71.92 & 57 & 28.08 & 203 & 0.0000 & 49.06 & 0.047 \\
\hline Have no access to credit & 65 & 36.52 & 113 & 63.48 & 178 & & & \\
\hline Total & 211 & 100 & 170 & 100 & 381 & & & \\
\hline
\end{tabular}

Source: Own computation 2019 significant at 5\%

\subsection{Econometric Analysis on Determinants of Poverty}

To decide whether to use Logit or probit model, both logit and probit regression models were compared by the researcher by using, Akaike information criterion (AIC) and the Bayesian information criterion (BIC). Accordingly, (AIC) for logit=167.9196 which is < (AIC) for probit=170.315. And (BIC) for logit=227.0615 which is $<$ (BIC) for probit=229.4569. The model with less (AIC) and (BIC) is preferable.

As introduced in the model specification part, a Logit model was employed to analyze determinants of poverty. This model is appropriate when we assume the random components of response variables follow binomial distribution \& when most variables are categorical responses. The suitability of the chosen model for econometric analysis very much depends on how much it predicts from the actual observation or what percent of the actual observation is really predicted by the model. There are no fixed points as to judge the model as a best or bad predictor yet it is generally agreed that a model with its overall predictive power of three percent or more is good (Mangus et al., 2006). Therefore, to assess whether or not the model fits the data, the researcher used different tests.

\subsubsection{Diagnostic test of the model test}

Prior to the estimation of the model parameters, it is crucial to look into the problem of multicolinearity or association among the potential candidate variables. In cross sectional data the problem of multicolinearity is a serious problem to checks this use the VIF if the VIF values for continuous variable equal to 10 or greater than 10 there is an association between the continuous variables has problems of multicolinearity. But in this research the average VIF is 3.84 i.e. it is less than 10 therefore, there is no multicolinearity problems see on the appendix (3) The values of VIF for continuous variables were found to be small (i.e. VIF values less than 10). To avoid serious problem of multicolinearity, it is quite essential to omit the variable with value 10 and more from the logit analysis. Based on the VIF result, the data have no serious problem of multicolinearity. As a result, all the continuous explanatory variables were retained and entered in to logistic analysis.

Contingency coefficients were also used to check for the degree of association among the discrete variables. In relation to the dummy variables, the contingency coefficients also less than 0.75 to a dummy variables. There for, there are no problems associated among the discrete variables. The values of contingency coefficient ranges between 0 and 1 . With zero indicating no association between the variables and values close to 1 indicating a 
high degree of association. Accordingly, the results of the computation reveal that there was no serious problem of association among discrete explanatory variables. Hence, all the discrete variables were entered into logit analysis.

\subsubsection{Model Results and Interpretation}

After the above tests, model estimation was taking place using STATA13.1 software. The model result of the determinant factors of the socio economic and demographic factors are presented.

Table 4.13. Logistic regression for poverty using different variables Logistic regression

$$
\begin{aligned}
& \text { Number of obs }= \\
& \text { LR chi2 }(14)=384.29 \\
& \text { Prob }>\text { chi }=0.0000
\end{aligned}
$$

Log likelihood $=-69.734016$

Pseudo R2 $=0.7337$

\begin{tabular}{|l|l|l|l|l|l|}
\hline Poverty & Odd Ratio & Std. Err. & $\mathrm{Z}$ & $\mathrm{P}>|\mathrm{z}|$ & Marginal effect \\
\hline Agehh & 1.079151 & .0234629 & 3.25 & 0.001 & .0109689 \\
\hline Sexhh & 1.69028 & .4932171 & 1.06 & 0.287 & .1230538 \\
\hline Famszhh & 1.345845 & .1094322 & 2.71 & 0.007 & .0442547 \\
\hline Eduhh & .4996601 & .2759816 & -2.51 & 0.012 & -.1077406 \\
\hline Inch & .9989935 & .0003392 & -2.97 & 0.003 & -.0002974 \\
\hline Marstsh & 2.693524 & .3485554 & 2.84 & 0.004 & .1717844 \\
\hline Housten & 5.903803 & .4810534 & 3.69 & 0.000 & .3222859 \\
\hline Helstshh & .780391 & .5772463 & -0.43 & 0.668 & -.0195616 \\
\hline Savhh & .9983822 & .00087 & -1.86 & 0.063 & .0001125 \\
\hline Emplstsh & 4.169843 & .5134118 & -2.78 & 0.005 & -.2827994 \\
\hline Acstbsce & 1.214754 & .4506121 & 0.43 & 0.666 & .0014925 \\
\hline Wtrsrce & 1.648999 & .4911122 & 1.02 & 0.308 & .0986182 \\
\hline Acstcrts & .3606601 & .5129628 & -1.99 & 0.047 & -.1526096 \\
\hline Rururmg & 1.519274 & .3360361 & 1.24 & 0.213 & .0597605 \\
\hline cons & .0140183 & 1.518217 & -2.81 & 0.005 & .0109689 \\
\hline
\end{tabular}

Source: Own computation 2019 significant at $* * * 1 \%, * 5 \%$ and $10 \%$ level of significances.

From the above table(Table 4.13), fourteen explanatory variables were regressed and nine of the variables were found statistically significant; at 1 percent (age of households, income of house hold head, marital status of households, house tenure of households, households family size and employment), 5 percent (educational level of households and access to credit) and 10 percent (saving). Since the coefficient of sex, health status, water, access to basic service and rural-urban are not statistically significant and rather inconclusive.

Examination of the Logit maximum-Likelihood estimates demonstrates that the variable gender (sex), age, marital status, employment, family size, water service, house tenure, basic service and rural-urban migration are positively related with the probability of being poor. On the other side, variables like, education, income of the household, health status and access to credit and Saving are inversely related with the probability of being poor.

The explanation of the logit results based on the coefficient of the model in which tells by what factor the dependent variable changes whenever a unit change occurs in independent variables. The analysis is useful, first, to verify the relative role of the various factors in determining poverty status, and second, to assess the potential impact that policy induced changes in these factors are likely to have on the probability of being poor ,holding other things constant.

As we can see in the table 13.4 above the logit result shows that the coefficient of age is positive (1.08), which mean the households probability of being poor is increased by 1.08 with an increase in age by one year. The productivity theory states that productivity and income would be low at relatively younger age, increases at the middle age and then decreases again at the old age. As a result, poverty would be high at younger age and decreases at middle age and then increases at old age. Its coefficient is statistically significant. Therefore, age is the main determinants of poverty in the study area. This result was supported by Mohammed (2009) in Woldia. Household size has significant positive coefficient. The bigger the household size, the higher the probability of being poor. The positive result of the variable is due to the quality of household members. The reason is that either many of them are not working (many children and elderly) or they are being remunerated compensated poor by which in the totality leads to a reduction in the per capita expenditure. As the number of family size of the household increased by one person, keeping all other variables constant, the households probability of being poor increases by a factor of 1.35 . The result is consistent with the theory that says household size positive relationship with poverty that as the household size increase the probability of the household to be fallen in poverty increases. For example Fagernäs and Wallace (2003) in Sierra Leone, explained that poorer households tended to be larger in household size than non-poor households. This assures that addition of a household member above the average family size pushes the household to the poverty trap significantly in the study area. 
Marital status of household also shows statistically positive significant result, implying that as the household get married, keeping other variables constant, the households probability of being poor decreased by factors of 2.69. These mean that when people get in to marriage, the probability of falling in to poverty reduces. The household can use the advantages of economies of scale and marriage can bring additional work force that helps to increase the household income. This founding is supported by Getachew(2009) in Gondar.

The coefficient of income is negative and statistical significant at $1 \%$ level of significance and affect on household poverty in the study area. It implies that as per household's income increases, purchasing power of the household increases, saving increases and achieving the minimum calories "requirement" lead probability of falling into poverty decreases. Economic theory tells that a household with a relatively better income will lead a better life and hence reduces the poverty. It is expected that household income affect urban poverty negatively. This outcome confirmed by Alemayhu in Kenya,Getachew(2009) in Gondar and et,al (2009).

The variable Educational level reveals a significant determinant of the probability of a household being poor. Education can serve as an important tool for bringing up out from poverty. The higher the educational attainment of the household head, the lower the household's probability of being poor. Overall, in the study area as expected, education has statistically significant and carries negative coefficient. Education also expected to lead to increased earning potential and improve occupational and geographical mobility of labor. Household educational level and poverty has negative relationship was found statistically significant, to influence poverty in Shashemene, at 95\% level of confidence interval. Holding other variables constant, educated household head has higher probability of escaping from poverty. With a unit increase in the household heads level of education, the households probability of falling in to poverty decrease by 0.50 and vice versa. Therefore, it is the most determinants of poverty in the study areas and serves as an important place in formulating poverty reduction strategy. This results similar with the founding of Alemayehu (2003) in Kenya,Getachew,et,al(2009).

The negative value of household employment type indicates that as households are working in professional occupations that is in public, the probability of being poor decreases, while the probability of households who engaged in an informal work to being poor increases. Households are assumed to earn more income in a formal and permanent work type than the informal work types. The variable household employment type logit estimation shows negative and statistically significant at $10 \%$ level of significance outcome, implying that as household public employment increases by one, while the value of all other variables remaining constant households probability of being poor decreases by 4.17 factors.

The coefficient of variable House tenure is positive and statistical significant coefficient. Because if households do not have their own house they are obliged to spend additional cost for housing rent, in turn, affects the income of a household. As a result, poverty will aggravate. As household not owning a house increases by one, other things remain constant the probability of being poor will be increases by 5.90 factors. This was confirmed with the founding of Mohammed (2009) in Woldia.

The variable saving of households reveals a significant determinant of the probability of a household being poor. The variable has negative relationship with poverty and significant at $1 \%$ level of significances. From the model a unit increases in the saving of household the values of other variable remain constant the probability of being poor decreases by 0.998 factor.

\section{CONCLUTION AND RECOMMENDATION}

\subsection{Conclusion}

The objective of the study was to assess determinants of household poverty and its relationships with urban poverty in Shashemene town. Both primary and secondary sources were used to carry out the study. A total of 381 household heads were randomly selected. The systematic random sampling was used to select households from the 8 sub-towns based kebele on registration. The research used the cost of basic needs approach in the identification of the poor from the non poor and $2300 \mathrm{kcal}$ as the minimum calorie required per adult equivalent per day in Ethiopia. Based on this approach the study found out of 381, surveyed households 170(44.62\%) of them were found below the poverty line. Variables, which we attempted to analyze household poverty in terms of household specific were selected and analyzed. These variables were analyzed through descriptive statistics and Econometrics model. A Logit model was used to compute the relationship between some selected determinants and poverty. The variables age of households, income of house hold head, marital status of households, house tenure of households, household's family size and employment were significant at 1 percent. Variables; educational level of households and access to credit were significant at 5 percent and saving at 10 percent. In general, it is concluded that urban poverty is multidimensional and has interrelated factors. That means one variable may be a cause and consequence simultaneously.

\subsection{Recommendations}

Since income is one of the determinants which are negative and significant in the study area, the, ways of diversifying the means of increasing household's income should be introduced. From this side, both the 
community members and the government should have the joint effort and responsibility to find possible remedies. One ways of doing this is through expanding the entrepreneurship skill of the local communities. Moreover, expansion of Micro and Small Scale Enterprises through inter connecting them with the Micro Finance Institution in the town could be used as one mechanism.

Education is also an important determinant of household poverty in the study area. Thus, promotion of education is central in addressing problems of poverty in the town. Specifically, higher education like college and University is found to be a principal in reducing poverty in Shashemene town. There are different private colleges in the town but, with limited departments. In general, the creation of human capital in the shape of better education increases the productivity/income of the poor.

Household size was positively and significantly correlated with poverty in Shashemene as the study shows. This has a clear implication for the residents of the town in that households with large size will fall in poorer sections easily than those who have not. Thus, in order to minimize such problems, family plans and giving awareness education for couples be provided by the concerned bodies in collaboration with religious leaders. In this regard the town's health service should play a great role. Poverty alleviation efforts should be made through the broad-based planning to increase real incomes of residents. This can be done through secure employment creation. The principal route out of urban poverty is sustainable work that generates better income. There is a need to develop and promote micro and small-scale enterprises relating to households skill, household age and market opportunities. But it is impossible to build enterprises without access to sufficient credit. So efforts should be made for households to acquire credit based on real situation of the society like religions affiliation to credit with interest and others. Hence, microfinance activities will go hand in hand with entrepreneurship enabling the poor to borrow for production purposes, save and build their assets and as a result poverty will be reduced.

Households use their house to perform different production and service activity that generate income. Therefore, encouraging and supporting households to have their own house should another remedial measure to minimize and alleviate urban household poverty. This can be in the form of free and fast land delivery for housing construction, affordable credit facility, building the condominium house. This requires the companied efforts of governments, city administration and micro finance institutions should be needed. Even if it is not significant, since rural urban migration of the household have positive relation with the probability to being poor, the concerned bodies should control it through launching the means and or accessing them to the social service is the resolution. Food poverty line for Shashemene town was found to be higher than the national food poverty line because of higher price for food items prevailing in the study area, which intern escalates the cost of living. This makes urban dwellers unable to afford food items. Hence, it's good to organize the community member into consumer's cooperatives so as to help them get consumer commodities at reasonable prices. Finally all these will help to reduce poverty in the town. For this, a joint effort is needed at every level and kind of activities from the government, non-governmental, community based organizations, researchers, the poor themselves, and from any interested stakeholder(s).

\section{References}

Alemayehu et al, (2005).Determinants of Poverty in Kenya: A Household Level Analysis Universityof Connecticut, Department of Economics, Working Paper 2005-44

C.R.Kothari (2004).Research Methodology Methods and Techniques, Second Revised Edition University of Rajahstan, Jaipur(India) New Age International (P) Ltd., Publishers.

Esubalew (2006). Determinants of Urban poverty: the Case of Debre Markos, Ethiopian Economics Association Proceeding of the fifth International Conference on the Ethiopian Economy, volume two, P. 37 -60. Addis Ababa, Ethiopia.

Food and Agriculture Organization -UN (2006) State of Food Insecurity in the World Accessed at http://www.fao.org/docrep/009/a0750e/a0750e00.htm

Getachew,(2009), Determinants of households Poverty: The case of Gondar city.

Gujarati D., (2004) Basic Econometrics. Fourth Edition, New York, McGraw-Hill,Inc.

Human Development Report 2003. New York, Oxford University Press. Accessed at http:/hdr.undp.org/en/reports/global/hdr2005/(2006).Human Development Report, 2006 Accessedathttp://hdrundp.org/en/reports/global/hd2006.

Magnus, A., Anders E. and Ari K., 2006. Determinants of Poverty in LAOPDR, Working Paper223, Stockholm, Sweden.

Mohammed T. (2009), Determinants of Household Poverty: the case of Woldia town, M.A. Thesis, Ethiopian Civil Service Collage Urban Management Masters Program unpublished.

MoFED, (2002). Development and Poverty Profile of Ethiopia, Welfare monitoring unit, Addis Ababa Ethiopia. MoFED, (2007). Annual Progress Report 2005/06. Addis Ababa.

MoFED,(2013), Development and Poverty in Ethiopia 1995/6-2010/11, p. 2-3. Addis Ababa. 
PASDEP (2006), Plan for Accelerated and Sustainable Development to End Poverty (2006-2010), Addis Ababa Ethiopia.

Shashemene town Planning and Economic Development (2017).Preliminary Study on the Socioeconomic Status of the Town (unpublished, translated Version).

Shashemene town Administration, (2017). Shashemene town physical and socio-economic profile(unpublished).

Tadesse (1999)."Determinants and Dynamics of Urban Poverty in Ethiopia. Ethiopian Journal of Economics 8, no. $1: 61-82$

UNDP, (2008).Human Development Report 2007. New York, Oxford press.

UNDP, http://hdr.undp.org, UNDP, (2018).

World Bank, (2007). Ethiopia accelerating equitable growth country economic memorandum, part two: Thematic Chapters, Report no. 38662-ET WashingtonDC

World Development Report.(2000).Attacking Poverty. New York, Oxford University Press.

World Development Report,(2006). Attacking Poverty.Oxford University Press. World Development Report, Washington, Dc

World Bank (2013). Development and Poverty Profile of Ethiopia, Addis Ababa. 